\title{
Is RAF1 protein from Synechocystis sp. PCC 6803 really needed in the cyanobacterial Rubisco assembly process?
}

\author{
Piotr Kolesinski $^{1} \cdot$ Malgorzata Rydzy $^{1} \cdot$ Andrzej Szczepaniak $^{1}$
}

Received: 5 October 2016 / Accepted: 2 January 2017 / Published online: 20 January 2017

(C) The Author(s) 2017. This article is published with open access at Springerlink.com

\begin{abstract}
Ribulose-1,5-bisphosphate carboxylase/oxygenase (Rubisco) is responsible for carbon dioxide conversion during photosynthesis and, therefore, is the most important protein in biomass generation. Modifications of this biocatalyst toward improvements in its properties are hindered by the complicated and not yet fully understood assembly process required for the formation of active holoenzymes. An entire set of auxiliary factors, including chaperonin GroEL/GroES and assembly chaperones RbcX or Rubisco accumulation factor 1 (RAF1), is involved in the folding and subsequent assembly of Rubisco subunits. Recently, it has been shown that cyanobacterial RAF1 acts during the formation of the large Rubisco subunit (RbcL) dimer. However, both its physiological function and its necessity in the prokaryotic Rubisco formation process remain elusive. Here, we demonstrate that the Synechocystis sp. PCC 6803 strain with rafl gene disruption shows the same growth rate as wild-type cells under standard conditions. Moreover, the Rubisco biosynthesis process seems to be unperturbed in mutant cells despite the absence of RbcL-RAF1 complexes. However, in the tested environmental conditions, sulfur starvation triggers the degradation of RbcL and subsequent proteolysis of other polypeptides in wild-type but not $\Delta$ rafl strains. Pull-down experiments also indicate that, apart from Rubisco, RAF1 co-purifies with phycocyanins. We postulate that RAF1 is not an obligatory factor in cyanobacterial Rubisco assembly, but rather participates in environmentally regulated Rubisco homeostasis.
\end{abstract}

Piotr Kolesinski

piotr.kolesinski@uwr.edu.pl

1 Laboratory of Biophysics, Faculty of Biotechnology, University of Wroclaw, F. Joliot-Curie 14a, 50-383 Wroclaw, Poland
Keywords RAF1 - Rubisco - Assembly chaperones · Carbon fixation $\cdot$ Cyanobacteria

\section{Introduction}

Ribulose-1,5-bisphosphate carboxylase/oxygenase (Rubisco) catalyzes the first reaction of the Calvin-Benson-Bassham cycle-incorporation of carbon dioxide into a sugar substrate, synthesizing two 3-phosphoglycerate molecules as a product. As this enzyme plays a significant role in carbohydrate and, in a broader range-biomass synthesis, it remains the center of interest in agricultural production and biofuel technology. The catalytic inefficiency of Rubisco, manifested both in the slow rate (3-12 s ${ }^{-1}$; Sage 2002) and possibility of erroneous incorporation of oxygen into RuBP resulting in the formation of toxic phosphoglycolate, makes this enzyme a desirable target for enhancement by directed mutagenesis. However, the establishment of a feasible and easy screening method for promising mutations is still hindered by the complicated and not fully understood Rubisco biosynthesis process, especially for the more complex form I of the enzyme. This form, which is met in eukaryotic photosynthetic organisms as well as in cyanobacteria, is built of eight large (RbcL) and eight small (RbcS) subunits, which have to be properly folded and then assembled in a step-wise manner. An entire set of auxiliary proteins involved in Rubisco biogenesis has been identified and functionally characterized. It is postulated that to achieve a proper tertiary structure $\mathrm{RbcL}$ requires the action of chaperonin (chloroplast Cpn60/Cpn20/Cpn10 or prokaryotic GroEL/GroES; Barraclough and Ellis 1980; Goloubinoff et al. 1989). Moreover, before that stage, a specific DnaJlike factor-Bsd2, found in eukaryotic chloroplasts seems to be crucial during the folding of the $\mathrm{N}$-terminal domain 
of the large Rubisco subunit (Brutnell et al. 1999; Doron et al. 2014). To form the octameric core of Rubisco, properly folded RbcLs first need to be dimerized, and to achieve this goal the participation of the so-called assembly chaperones is required. These factors enable proper mutual orientation of the hydrophobic surfaces of RbcL monomers which would tend to aggregate without these guiding proteins. Although two such polypeptides have been identified-RbcX and Rubisco accumulation factor 1 (RAF1), their modes of action are slightly different. The central cleft of $\mathrm{RbcX}$ recognizes a specific sequence in the $\mathrm{C}$-terminal tail of one RbcL subunit, whereas its apical part provides an additional waypoint for appropriate positioning of the second RbcL subunit (Saschenbrecker et al. 2007; Bracher et al. 2011). RAF1, on the other hand, binds along the RbcL dimer interface, which suggests an alternate way of guiding the arrangement of bilateral large Rubisco subunits (Hauser et al. 2015). Recently, another Rubisco assembly chaperone-RAF2, has been identified. Although its structure has been solved (Wheatley et al. 2014), both its exact physiological function as well as its mode of action remain obscure. However, it may act during the addition of small Rubisco subunits into the octameric core of the enzyme (Feiz et al. 2014).

Although RbcX as well as RAF1-encoding genes are present in both plant and cyanobacterial genomes, the requirement for their participation in Rubisco assembly seems to be kingdom-related. Except for Rubisco from Synechococcus elongatus PCC 7942 or its derivatives, where the biosynthesis process seems to be at least partially RbcX-independent (Emlyn-Jones et al. 2006), cyanobacterial holoenzymes rely on this assembly chaperone to reach a properly folded and active state (Onizuka et al. 2004; Li and Tabita 1997). In contrast, there is still no indication of the requirement for $\mathrm{RbcX}$ involvement in plant Rubisco assembly, although it may fulfill this function toward cyanobacterial enzymes (Kolesinski et al. 2011). During biosynthesis of plant Rubisco, the assembly machinery instead depends on the RAF1 protein, which is confirmed by the lethality of RAF1-encoding gene disruption in maize (Feiz et al. 2012) as well as the requirement for Arabidopsis thaliana RAF1 for proper biogenesis of Arabidopsis enzymes in tobacco cells (Whitney et al. 2015). Although the ability of RAF1 to promote prokaryotic RbcL assembly in vitro as well as in Escherichia coli is indisputable (Hauser et al. 2015; Kolesinski et al. 2014), the physiological function of this factor in cyanobacterial cells remains unclear.

Here, we report that RAF1 is not required in the biogenesis of cyanobacterial Rubisco from Synechocystis sp. PCC 6803. The RAF1 deletion strain of this cyanobacteria shows no significant perturbation in the growth rate or Rubisco amount under standard cultivation conditions.
However, under conditions of sulfur depletion, the starvation phenotype appears to be delayed and milder in the $\Delta$ rafl mutant than in wild-type cells. Also, except for large and small Rubisco subunits, RAF1 co-precipitates with both $\alpha$ and $\beta$ subunits of phycocyanin during pull-down experiments. We postulate that, in contrast to the plant cell where this factor plays a pivotal role in Rubisco assembly, its cyanobacterial homolog fulfills an auxiliary function participating in environmental condition-dependent regulation of Rubisco homeostasis.

\section{Materials and methods}

\section{Growth conditions}

Synechocystis sp. PCC 6803 were cultivated on BG-11 medium (Rippka 1988) at $30^{\circ} \mathrm{C}$ under continuous illumination of $50 \mu \mathrm{E} \times \mathrm{m}^{-2} \times \mathrm{s}^{-1}$. Environmental stresses were applied to the cultures of $\mathrm{OD}_{730} \sim 1$ as described further. For salt stress, BG-11 medium was supplemented with $0.5 \mathrm{M}$ $\mathrm{NaCl}$ according to Kanesaki et al. (2002) and cells were grown for an additional $72 \mathrm{~h}$. Oxidative stress was carried out as described by $\mathrm{Li}$ et al. (2004) — by the addition of $\mathrm{H}_{2} \mathrm{O}_{2}$ to the medium to a final concentration of $1.5 \mathrm{mM}$ and incubation for a subsequent $30 \mathrm{~min}$. Sulfur depletion was implemented by the replacement of sulfate salts in BG-11 medium by corresponding chlorides of the same concentration. Cells of appropriate $\mathrm{OD}_{730}$ were washed and next re-suspended in sulfur-free medium and then cultivated for another $72-144 \mathrm{~h}$. The optical density of all re-suspended cells measured at $730 \mathrm{~nm}$ was set to the same value of 0.5 . For sulfur repletion, stressed cells after 72, 120, or $144 \mathrm{~h}$ were supplemented with $\mathrm{MgSO}_{4}$ added to the cultures on BG-11(-S) medium to the final concentration of $75 \mathrm{mg} / \mathrm{l}$, i.e., an equivalent amount of sulfate to that in standard BG-11. After $\mathrm{MgSO}_{4}$ supplementation, cultures were carried out for an additional $48 \mathrm{~h}$. To compare growth and pigment absorbance of cells after sulfate repletion, wild-type and mutant cells starved for $144 \mathrm{~h}$ were set to the same $\mathrm{OD}_{730}$ value of 0.8 and cultivated for another $48 \mathrm{~h}$ after addition of $\mathrm{MgSO}_{4}$. Before and after sulfate supplementation absorption spectra of wild-type and $\Delta$ rafl cells were measured.

\section{Transformation of cyanobacteria}

Transformation of Synechocystis sp. PCC 6803 cells was performed according to the procedure described by Grigorieva and Shestakov (1992). In short, cells of $\mathrm{OD}_{730^{\sim}} 1$ were centrifuged for $10 \mathrm{~min}$. at $3000 \times g$ at RT and resuspended in fresh BG-11 medium to $\mathrm{OD}_{730}$ of ca. 40 . For each $0.5 \mathrm{ml}$ of cell suspension, $50 \mu \mathrm{g}$ of circular, 
water-dissolved plasmid was added. The mixture was incubated overnight at RT in darkness with gentle rotation and then propagated on solid BG-11 medium supplemented with $5 \mathrm{mM}$ glucose and $25 \mu \mathrm{g} / \mathrm{ml}$ kanamycin. Colonies appeared after 7 to 10 days. To achieve full segregation of the introduced mutation, cells underwent subsequent passages on BG-11 medium with increasing kanamycin concentrations (from 25 to $50 \mu \mathrm{g} / \mathrm{ml}$ ). The genetic homogeneity of the obtained strain was confirmed using PCR with $6803 \mathrm{KOFw}$ and $6803 \mathrm{KORv}$ primers (sequences are listed in Table 1). Homogenous mutants were further cultivated on BG-11 medium without the addition of either glucose or an antibiotic.

\section{Nucleic acid manipulation}

Cyanobacterial genomic DNA was isolated according to the procedure described by Wu et al. (2000). All plasmid vectors were purified using a GeneMATRIX plasmid miniprep DNA purification kit (EURx, Gdansk, Poland).

For construction of rafl, deletion plasmid 2357 bp DNA fragment containing the sll0102 gene with overlaps was amplified using Phusion polymerase (Thermo Fisher Scientific, Waltham, MA, USA), rafSynKOFw and rafSynKORv primers, with Synechocystis genomic DNA as a template. Obtained DNA was purified, digested with EcoRI and HindIII nucleases, and cloned into a pTZ57R vector (Thermo Fisher Scientific) digested with the same set of restriction enzymes. The constructed vector was digested with BstEII and $N c o$ I enzymes, resulting in the removal of the $657 \mathrm{bp}$ fragment of the RAF1-encoding gene. The deleted fragment was replaced with a kanamycin resistance gene with its own promoter fragment amplified with Phusion polymerase, $\mathrm{pKmFw}$ and KmRv primers, and a pET-24b vector (Novagen, Darmstadt, Germany) as a template, which was purified and subsequently digested with BstEII and NcoI nucleases. The obtained plasmid pTZ57raf1KO was directly used for Synechocystis transformation.

For over-expression of $\mathrm{N}$ - and C-terminally Streptagged as well as untagged variants of rafl gene from Synechocystis sp. PCC 6803, DNA fragments were amplified with the use of Phusion polymerase, genomic cyanobacterial DNA, and a suitable set of primers (raf1NStFw and raf1Rv; raf1Fw and raf1CStRv; or raf1Fw and raf1Rv, respectively). The obtained DNA fragments were purified and digested with $N d e$ I and EcoRI nucleases and cloned into a pET-22b vector (Novagen, Darmstadt, Germany), cut with the same set of enzymes, resulting in plasmids termed pET22raf1NSt, pET22raf1CSt, and pET22raf1. The $r b c X$ gene from Synechocystis sp. PCC 6803 was amplified as described above with the use of rbcXFw and rbcXRv primers, and cloned into NdeI and EcoRI sites of a pET-22b vector, resulting in a pET22rbcX plasmid.

For the co-expression experiment, the desired genes were cloned into a pUC18 vector (Thermo Fisher Scientific) or its derivatives. Plasmid pUC18(LR) 6803 carrying $r b c L$ and rafl genes from Synechocystis sp. PCC 6803 was constructed by subsequent cloning of rafl and
Table 1 List of oligonucleotides used in this study

\begin{tabular}{ll}
\hline Name & Sequence \\
\hline $6803 \mathrm{KOFw}$ & GAAGGCAGGTTACGGTGC \\
$6803 \mathrm{KORv}$ & CCTTTAGCTTACTCCAAG \\
rafSynKOFw & TATGAATTCTGAATAGGAAAAGTTCCAC \\
rafSynKORv & TATAAGCTTGACGATGGCAAGATGG \\
pKmFw & AAAGGTTACCGTTAAGGGATTTTGGTCATG \\
$\mathrm{KmRv}$ & AAACCATGGCTTAGAAAAACTCATCGAGC \\
raf1Fw & AAACATATGACCCATTCCCCTGAATCC \\
raf1Rv & AAAGAATTCTAATCATCCATTTGCCATGGTTC \\
raf1NStFw & AAACATATGTGGAGCCACCCGCAGTTCGAAAAAGCGACC \\
raf1CStRv & CATTCCCTGAATCC \\
rbcXFw & AAAGAATTCCTATTTTCGAACTGCGGGTGGCTCCATGC \\
rbcXRv & ATCATCCATTTGCCATG \\
rbcL6803Fw & AAACATATGTTCATGCAAACTAAGCACATAGC \\
rbcL6803Rv & AAAGAATTCTTAGGACGGGGGAGAATCGTTG \\
rbcL6803*Fw & CGAATTCGAGCTCGGTACCCATGGTACAAGCCAAAGCAGG \\
rbcL6803*Rv & ATTATTTCTAGAGGATCCCCGGTTTAGAGGGTATCCATGG \\
rbcL7942Fw & AAAGAATTCATGGTACAAGCCAAAGCAGG \\
rbcL7942Rv & AAACTGCAGTTAGAGGGTATCCATGG \\
\hline & AAAGGATCCGGGACTGCAGCTTTACAG \\
& AAATCTAGACCCCAGCGATAGTCAGAGG \\
&
\end{tabular}


then $r b c L$ genes. The rafl gene-containing fragment was digested from pET22raf1 with XbaI and HindIII enzymes and sub-cloned into pUC18 giving a pUC18raf1 plasmid. The Synechocystis rbcL gene was amplified as described above with the use of rbcL6803Fw and rbcL6803Rv. After the digestion of the pUC18raf1 plasmid with SmaI nuclease, the $r b c L$ gene was introduced with a Gibson Assembly Cloning Kit (New England Biolabs, Ipswich, MA, USA). Simultaneously, the $r b c L$ gene from Synechocystis was amplified with rbcL6803*Fw and rbcL6803*Rv primers and cloned into the EcoRI and PstI sites of the pUC18 plasmid resulting in a pUC18 $\mathrm{rbcL}_{6803}$ vector. To obtain plasmid pUC18 $\mathrm{L}_{7942} \mathrm{R}_{6803}$ carrying an rafl gene from Synechocystis sp. PCC 6803 and an $r b c L$ gene from S. elongatus PCC 7942, the $r b c L$ gene was amplified using rbcL7942Fw and rbcL7942Rv primers and cloned into the Bam HI and $\mathrm{XbaI}$ sites of the pUC18raf1 plasmid. Vector pUC18rbcL 7942 carrying an $r b c L$ gene from $S$. elongatus alone was constructed in a similar manner, but ligation was performed into the pUC18 plasmid instead of pUC18raf1. Vector pUC18 $\mathrm{L}_{\mathrm{Te}} \mathrm{R}_{6803}$ carrying an rafl gene from Synechocystis sp. PCC 6803 and an $r b c L$ gene from Thermosynechococcus elongatus was constructed by sub-cloning an raflcontaining fragment of pET22raf1 digested with $X b a \mathrm{I}$ and HindIII into the previously described pUC18rbcL plasmid (Tarnawski et al. 2008). pUC18 $\mathrm{L}_{\mathrm{Te}} \mathrm{X}_{6803}$ carrying an $r b c X$ gene from Synechocystis sp. PCC 6803 and an $r b c L$ gene from $T$. elongatus was constructed by sub-cloning an $r b c X$ containing fragment of pET22rbcX digested with $X b a \mathrm{I}$ and HindIII into pUC18rbcL.

\section{Protein expression and purification}

All proteins were overproduced in E. coli Rosetta cells in liquid LB medium supplemented with ampicillin $(100 \mu \mathrm{g} /$ $\mathrm{ml})$ and chloramphenicol $(25 \mu \mathrm{g} / \mathrm{ml})$ at $37^{\circ} \mathrm{C}$. Over-expression of tagged and untagged RAF1 variants was induced by the addition of $0.5 \mathrm{mM}$ isopropyl- $\beta$-D -thiogalactopyranoside (IPTG) to the cultures at an attenuance at $600 \mathrm{~nm}$ of approximately 0.6 , followed by incubation with vigorous shaking for the next $3 \mathrm{~h}$ at $37^{\circ} \mathrm{C}$. For induction of RbcLcontaining complexes as well as RbcLs alone over-expression, $0.1 \mathrm{mM}$ IPTG was used followed by incubation for the next $5 \mathrm{~h}$. After cultivation, cells were pelleted $(2000 \times \mathrm{g})$ for $10 \mathrm{~min}$ at $4{ }^{\circ} \mathrm{C}$, and frozen at $-20^{\circ} \mathrm{C}$ for further manipulations. All cells were disrupted by sonication in $20 \mathrm{mM}$ Tris pH 8.0, $100 \mathrm{mM} \mathrm{NaCl}, 1 \mathrm{mM}$ EDTA, $1 \mathrm{mM}$ phenylmethanesulfonyl fluoride (PMSF), and $2 \mathrm{mM} \beta$-mercaptoethanol, and the insoluble cell fraction was pelleted by centrifugation at $20000 \times g$ for $30 \mathrm{~min}$ at $4{ }^{\circ} \mathrm{C}$. All RAF1 variants were purified by subsequent ammonium sulfate precipitation, ion exchange chromatography, and size exclusion chromatography. Proteins were desalted with solid ammonium sulfate to $35 \%(\mathrm{w} / \mathrm{v})$ saturation followed by centrifugation at $20000 \times \mathrm{g}$ for $30 \mathrm{~min}$ at $4{ }^{\circ} \mathrm{C}$. The obtained pellets were dissolved in $20 \mathrm{mM}$ Tris $\mathrm{pH}$ 8.0, $2 \mathrm{mM} \beta$-mercaptoethanol, dialyzed against the same buffer, and then subjected to ion exchange chromatography using a Q-Sepharose column (GE Healthcare, Little Chalfont, UK) pre-equilibrated with $20 \mathrm{mM}$ Tris $\mathrm{pH}$ 8.0, $2 \mathrm{mM} \beta$-mercaptoethanol. Elution of RAF1 variants was conducted in a $0-500 \mathrm{mM} \mathrm{NaCl}$ gradient. Suitable fractions were concentrated with Amicon Ultra Centrifugal Filter Units (Merck Millipore, Billerica, MA, USA) and finally subjected to size exclusion chromatography with a Superdex 75 column (GE Healthcare) pre-equilibrated with $20 \mathrm{mM}$ Tris $\mathrm{pH} 8.0,150 \mathrm{mM} \mathrm{NaCl}$, $2 \mathrm{mM} \beta$-mercaptoethanol. The $\mathrm{RbcL}_{\mathrm{Te}}-\mathrm{RAF}_{6803}$ complex was purified the same way as RAF1 with the omission of the gel filtration step. The $\mathrm{RbcL}_{\mathrm{Te}}-\mathrm{RbcX}_{6803}$ complex and $\mathrm{RbcX}_{6803}$ were purified during the same purification procedure. Proteins were precipitated with ammonium sulfate to $30 \%(\mathrm{w} / \mathrm{v})$ saturation and subjected to purification on a Q-Sepharose column as described for RAF1 proteins. During the elution, the $\mathrm{RbcL}_{\mathrm{Te}}-\mathrm{RbcX}_{6803}$ complex-containing fraction is separated from the excess of $\mathrm{RbcX}$ protein (unbound RbcX represents ca. $75 \%$ of ammonium sulfate precipitated polypeptides). After the purification, all proteins were dialyzed against $10 \mathrm{mM}$ Tris $(\mathrm{pH} 8.0), 2 \mathrm{mM}$ $\beta$-mercaptoethanol. $\mathrm{RbcL}_{8}$ from T. elongatus was purified as previously described (Kolesinski et al. 2014). Rubisco $\left(\mathrm{RbcL}_{8} \mathrm{RbcS}_{8}\right)$ from $T$. elongatus was kindly provided by Beata Gubernator (Faculty of Biotechnology, University of Wroclaw, Poland).

\section{Cyanobacterial extract preparation and RAF1 pull-down}

After the cultivation, cyanobacterial cultures were pelleted by centrifugation at $3000 \times \mathrm{g}$ for $10 \mathrm{~min}$ at $4{ }^{\circ} \mathrm{C}$. Crude cell extracts were obtained by sonication in $20 \mathrm{mM}$ Tris $\mathrm{pH} 8.0$, $150 \mathrm{mM} \mathrm{NaCl}, 2 \mathrm{mM}$ PMSF, and $2 \mathrm{mM} \beta$-mercaptoethanol followed by centrifugation at $15000 \times g$ for $15 \mathrm{~min}$ at $4{ }^{\circ} \mathrm{C}$. RAF1 pull-downs were performed with the use of protein extracts from wild-type cells. For cell extracts containing $1 \mathrm{mg}$ of proteins, $20 \mu \mathrm{g}$ of N- or C-terminally Strep-tagged RAF1 was added and pre-incubated for $5 \mathrm{~min}$ at RT. After initial pre-incubation, $50 \mu \mathrm{l}$ of Strep-Tactin Superflow Plus resin (Qiagen, Hilden, Germany) was added and binding was carried out with gentle rotation for $15 \mathrm{~min}$ at RT. Resin was washed five times with wash buffer $(20 \mathrm{mM}$ Tris $\mathrm{pH}$ $8.0,150 \mathrm{mM} \mathrm{NaCl}$ ). Bound polypeptides were eluted using wash buffer supplemented with $2.5 \mathrm{mM}$ d-desthiobiotin. PAGE-separated polypeptides were excised from gels, trypsin-digested, and subjected to mass spectroscopy analysis at the Mass Spectroscopy Laboratory of Biophysics and 
Biochemistry Institute of the Polish Academy of Sciences (Warsaw, Poland).

\section{Protein electrophoresis and immunoblot analysis}

Before electrophoresis, the protein concentration in $E$. coli extracts was measured using Roti-Nanoquant reagent (Carl Roth, Karlsruhe, Germany). For measurement of protein concentration in cyanobacterial extracts, a DC Protein Assay kit (Bio-Rad, Hercules, CA, USA) was employed. Protein separation under denaturing conditions was performed using Tricine-PAGE (Schagger and von Jagow 1987), and for native PAGE a 10\% TGX FastCast Acrylamide Kit (Bio-Rad) was employed. Gels were Coomassiestained except visualization of polypeptides designated for MS analysis, which were silver-stained according to the procedure described by Mortz et al. (2001). For immunodetection, separated proteins were transferred onto a PVDF membrane and incubated with anti-RAF1 (1:2000 dilution for cyanobacterial extracts, 1:20,000 for E. coli extracts; raised against purified RAF1 proteins from Synechocystis sp. PCC 6803 by BLIRT, Gdansk, Poland), or anti-RbcL antibodies (1:2000 for cyanobacterial extracts, 1:10,000 for E. coli extracts; Agrisera, Vännäs, Sweden), and subsequently probed with secondary goat anti-rabbit antibodies conjugated with horseradish peroxidase (Sigma-Aldrich, St. Louis, MO, USA). Chemiluminescence detection was performed with a NOWA Kit (MoBiTec GmbH, Goettingen, Germany) on a ChemiDoc Imaging System (Bio-Rad). Calculation of band density was performed with ImageJ software (Schneider et al. 2012). The significance of results was determined with the Student's $t$ test $(P=0.05)$.

\section{Rubisco activity assay}

A Rubisco carboxylase activity assay was performed as previously described (Gubernator et al. 2008). Equivalents of cyanobacterial cell extracts containing $20 \mu \mathrm{g}$ of proteins were used for individual measurements.

\section{Results}

To show the physiological function of RAF1 proteins in cyanobacterial cells, we decided to perform rafl gene knock-out in a model organism-Synechocystis sp. PCC 6803. Disruption of the sll0102 gene encoding the RAF1 homolog was performed via double crossover with transformation plasmid pTZ57raf1KO, in which ca. $2 / 3$ of the rafl sequence was replaced by a kanamycin-resistance cassette (Fig. 1a). The introduced mutation underwent rapid segregation-after only two passages all tested lines showed genomic homogeneity toward rafl knock-out, as confirmed by PCR (Fig. 1b). To verify whether RAF1 is a crucial factor in cyanobacterial Rubisco biosynthesis, we compared the growth rates of wild-type and $\Delta$ rafl cells as well as the amount of RbcL and quality of RbcL-containing complexes in crude extracts from these lines. Disruption of the rafl gene did not result in any significant growth perturbations to mutated cyanobacterial lines under standard cultivation conditions (Fig. 1c), although they displayed a slightly increased tendency for adhesion to glass surfaces (i.e., flask bottoms) than wild-type cells (not shown). Immunodetection using anti-RbcL antibodies did not indicate significant differences for RbcL amounts in cell extracts from both wild-type and mutant lines or, in most cases, the presence of modified RbcL-containing complexes (Fig. 2). In addition, the results of Rubisco carboxylase activity measurements remained in agreement with densitometry analyses (Fig. 2d). At the same time, probing with anti-RAF1 antibodies confirmed the existence of at least four different RAF1-containing bands (two low- and two high-molecular weight) in wild-type cells and a lack of these structures in $\Delta$ rafl mutants. Potential co-localization of RbcL in such high-molecular weight RAF1-containing complexes was barely detectable and only under certain circumstances (see "sulfur starvation" panel in Fig. 3).

To test the possibility of whether RAF1 is an auxiliary protein required in Rubisco biosynthesis under certain environmental conditions, we decided to grow wild-type and mutated Synechocystis cells under conditions causing an increase in rafl transcript abundance, as shown by RNA microarray experiments (CyanoEXpress; http://cyanoexpress.sysbiolab.eu/; Hernandez-Prieto and Futschik 2012) $-\mathrm{H}_{2} \mathrm{O}_{2}$-induced oxidative stress and sulfur starvation. In addition, salt stress, which has been reported to negatively affect Rubisco stability (i.e., He et al. 2014), was also implemented. Cells were subjected to abiotic stress, disrupted and their crude extracts PAGE-separated and probed with anti-RbcL and anti-RAF1 antibodies. Among the tested conditions, only sulfur deprivation caused significant differences in the phenotypes of wild-type and $\Delta$ rafl lines (Fig. 3). While $\Delta$ rafl mutant seemed to be resistant to sulfur absence in the growth medium, at least on a polypeptide composition level, wild-type cells showed a severe starvation phenotype manifesting in degradation of high-molecular weight proteins, usually after 3 days. At the same time, the amount of RbcL in wild-type cells slightly decreased and its proteolytic products appeared, as judged by immunodetection against SDS-PAGE separated peptides. Observed phenotypes were not strictly repetitive. Alteration of polypeptide composition during starvation was rarely detected for higher density cells $\left(\mathrm{OD}_{730}>1.0\right)$; therefore, for further experiments cyanobacterial cultures diluted to $\mathrm{OD}_{730}$ of $0.5-0.6$ in sulfur-free medium were used. To test the decreased sulfur depletion susceptibility 
A

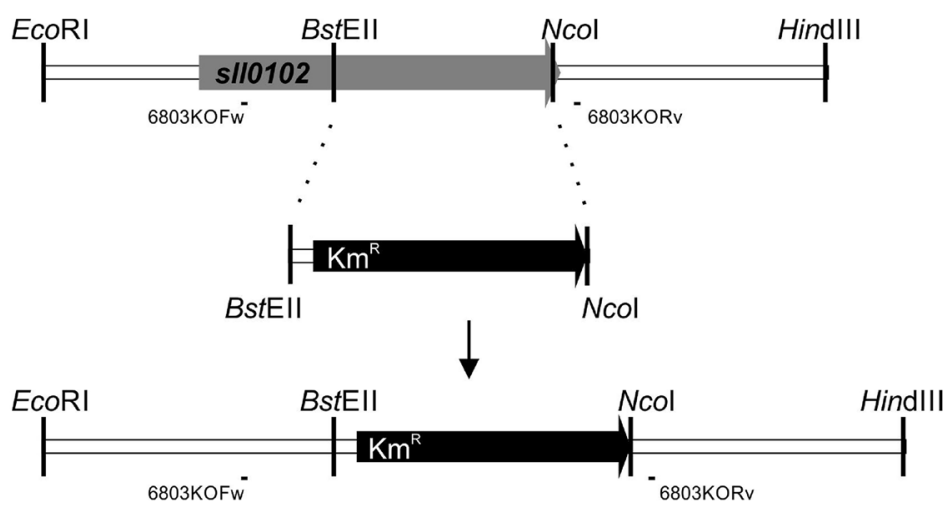

B

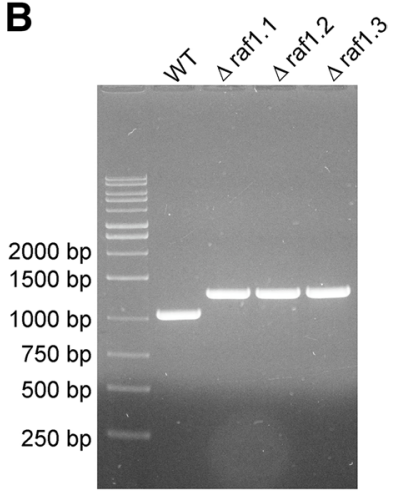

C

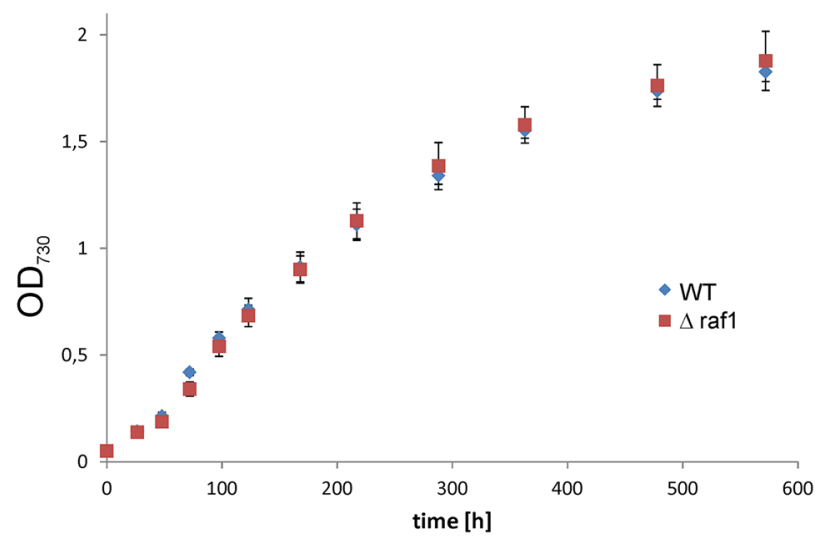

Fig. 1 Generation and growth analysis of Synechocystis $\Delta$ rafl mutant. a Scheme for insertional inactivation of sll0102 gene. The $657 \mathrm{bp}$-long fragment of this gene was replaced with a kanamycinresistance cassette. A construct was used for transformation of the wild-type cells to generate an rafl knock-out mutant. Hybridization positions of primers used for confirmation of the introduced muta-

of $\Delta$ raf1 mutants, cultivation on BG-11(-S) medium was prolonged to 7 days. While independent wild-type cultures displayed virtually the same phenotype after 3,5, and 7 days, a mutant polypeptide composition showed a mild phenotypic effect only after a week (Fig. 4a, b), although $\mathrm{RbcL}$ fragmentation was detected earlier. Independent experiments differed in terms of the time of the first observable protein degradation effect-in some cases increased proteolysis was time-shifted to 5 days. However, comparison of wild-type and mutant cells growing simultaneously always resulted in the same pattern- $-\Delta$ rafl never exhibited severe polypeptide fragmentation and its starvation phenotype appearance was always delayed when compared to wild-type culture. To test the survivability of starved cyanobacteria, cells after 3,5, and 7 days of treatment, respectively, were supplemented with sulfate and left for an additional 2 days of cultivation. A mild starvation phenotype of mutant cells manifested in slightly altered polypeptide composition, and lowered Rubisco amount was still tion were indicated. b Confirmation of mutation introduction (for 3 independent mutant lines) and homogeneity by PCR. c Comparison of growth rates of wild-type and $\Delta$ rafl Synechocystis cells in standard cultivation conditions monitored by measurement of $\mathrm{OD}_{730}$ (mean $\mathrm{OD}_{730}$ values for three independent cultures of each strain with standard deviation bars plotted against timescale)

visible after two days of sulfate implementation indicating limited adaptive abilities of Synechocystis $\Delta$ rafl (Fig. 4c, d). Moreover, mutant cells subjected to 7 days of treatment exhibited decreased growth rate in comparison to wild type after sulfate repletion (Fig. 4e, f). In addition, formation of fast-sedimenting cell aggregates was observed for starved $\Delta$ rafl strain but not for wild type (Fig. 4e).

We decided to verify whether cyanobacterial RAF1 is a part of the Rubisco degradation pathway instead of its assembly. To test this hypothesis, RAF1 pull-down was performed to find RAF1 interactors with indication to chaperones or proteolytic enzymes (e.g., Clp proteases). Since the standard immunoprecipitation approach provided low quality results due to suboptimal yield and high background, N- and C-terminally Strep-tagged RAF1 were added externally to cyanobacterial crude extracts. After elution of tagged RAF1 with potentially bound polypeptides, samples were SDS-PAGE separated and specific protein bands were identified by mass spectroscopy. Apart 


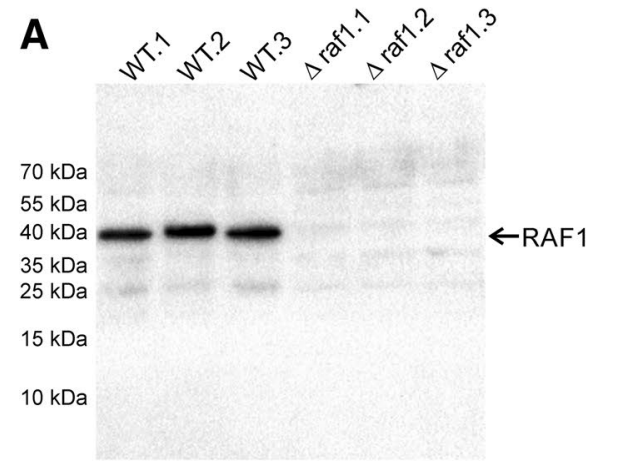

SDS-PAGE

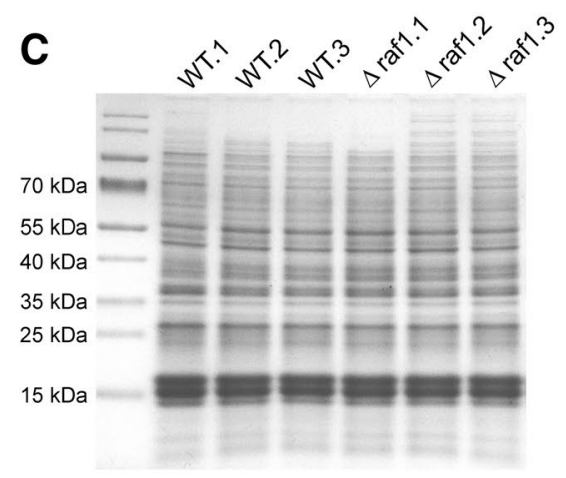

SDS-PAGE

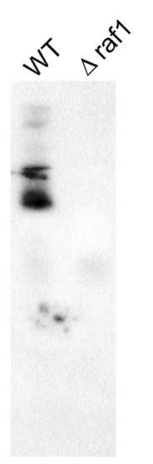

Native-PAGE

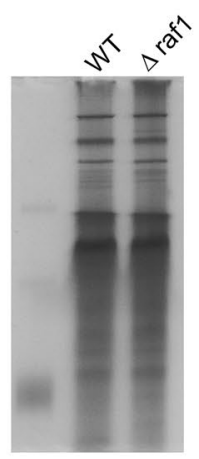

Native-PAGE

Fig. 2 Comparison of RbcL and RAF1 amounts and composition of RbcL- and RAF1-containing complexes in wild-type and $\Delta$ raf1 Synechocystis cells cultivated under normal conditions. A total of $20 \mu \mathrm{g}$ of protein extracts from wild-type and mutant cells were loaded per lane, separated under denaturing (SDS-PAGE; extracts from three independent cultures of wild-type as well as $\Delta$ rafl strains were used to compare RbcL amounts) or non-denaturing conditions (Native-

from Rubisco (both large and small subunits), RAF1 copurifies with Cpn60, DnaK2, and a relatively high amount of phycocyanin ( $\alpha$ and $\beta$ subunits; Fig. 5). No proteases or unfoldases were found among the identified putative interactors. In addition, C-terminally tagged RAF1 from Synechocystis sp. PCC 6803 does not co-purify with Rubisco, suggesting that exposition of its C-terminus may be crucial for interaction with RbcL.

To ensure that RAF1 homologs from Synechocystis sp. PCC 6803 fulfill the same function during Rubisco assembly in vitro and in E. coli cells as its counterparts from $T$. elongatus and S. elongatus sp. PCC 7942, a Rubisco biosynthesis assay was performed in bacterial cells. An rafl gene from Synechocystis was co-expressed in E. coli with an RbcL-encoding gene from the same organism as well as rbcLs from $T$. elongatus and $S$. elongatus. The obtained crude extracts and cell lysates from $E$. coli were separated using SDS-PAGE and subsequently subjected to immunodetection with anti-RbcL and anti-RAF1 antibodies (Fig. 6a). Cell extracts with confirmed soluble RbcL
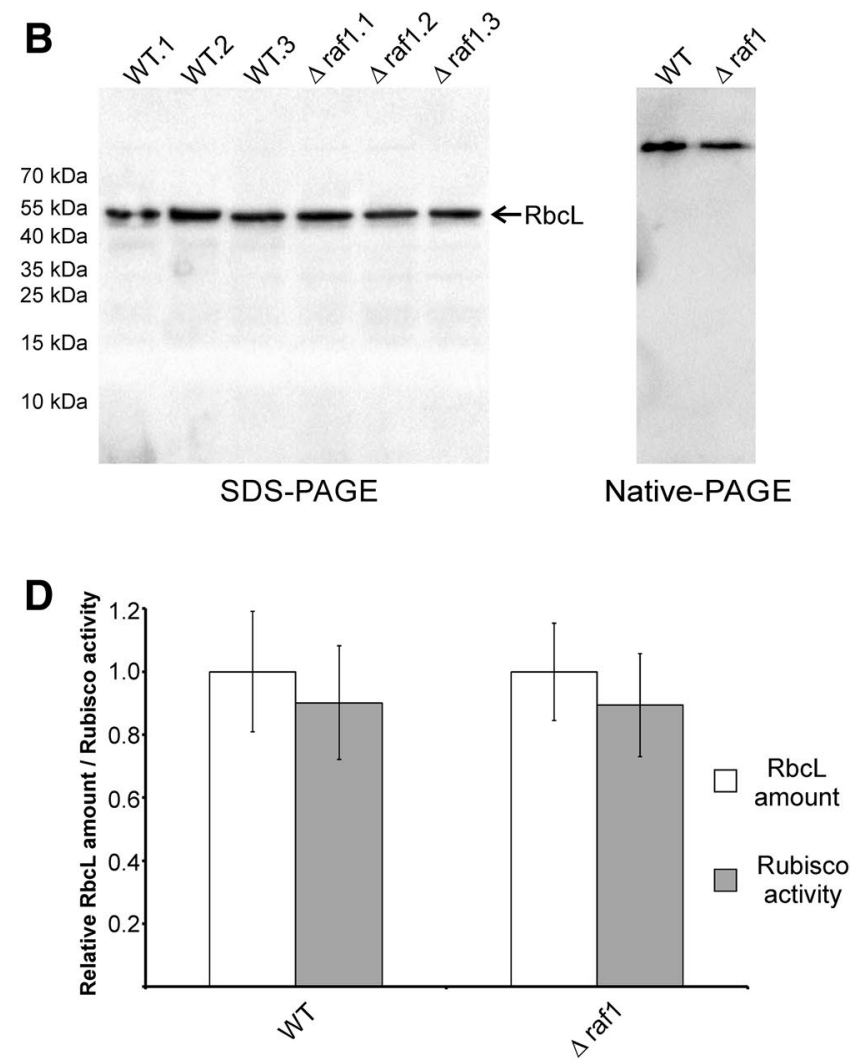

PAGE), and subjected to immunodetection using anti-RAF (a) or anti-RbcL (b) antibodies. As a loading control, Coomassie-staining of PAGE-separated extracts was used (c). Mean relative RbcL amount calculated by densitometric blot analysis and Rubisco activity in three independent cultures of each strain with standard deviation bars were compared using a bar graph (d)

presence were additionally separated under non-denaturing conditions and probed with anti-RbcL or anti-RAF1 antibodies. Synechocystis RAF1 promoted folding of its own RbcL resulting in formation of a complex exhibiting a migration pattern similar to those reported for T. elongatus (Kolesinski et al. 2014), or S. elongatus PCC 7942 (Hauser et al. 2015) $\mathrm{RbcL}_{2}-\mathrm{RAF}_{2}$ (Fig. 6b). In addition, it effectively showed the same function toward RbcLs from two other cyanobacteria ( $T$. elongatus and $S$. elongatus PCC 7942). However, in these cases only larger complexes resembling those identified previously as $\mathrm{RbcL}_{8}-\mathrm{RAF}_{8}$ (Hauser et al. 2015) were observed. Interestingly, spontaneous formation of a presumed octamer was observed for RbcL from $T$. elongatus alone. No such effect was visible for $S$. elongatus RbcL, despite its confirmed foldability. Unfortunately, $\mathrm{RbcL}_{6803}-\mathrm{RAF} 1_{6803}$ expression did not scale up to preparative volumes, therefore making it impossible to obtain a purified complex. However, it was possible to over-express in E. coli and purify stable complexes containing RbcL from $T$. elongatus with RAF1 or RbcX from 

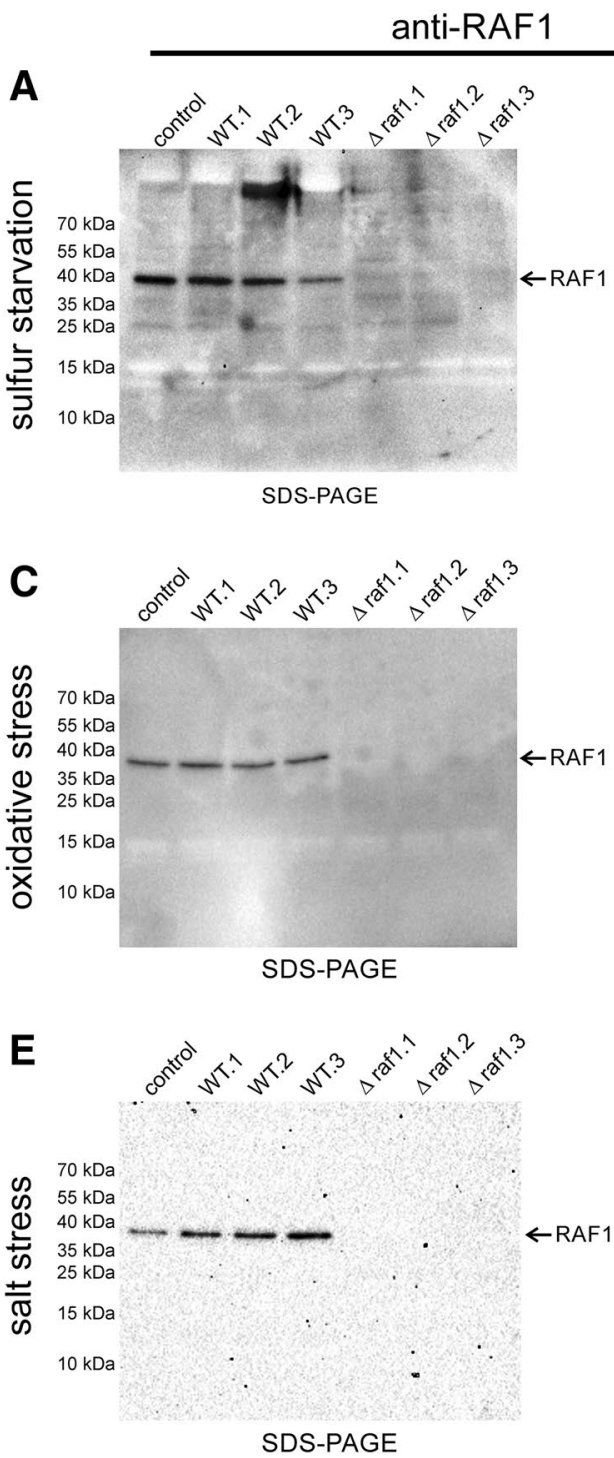
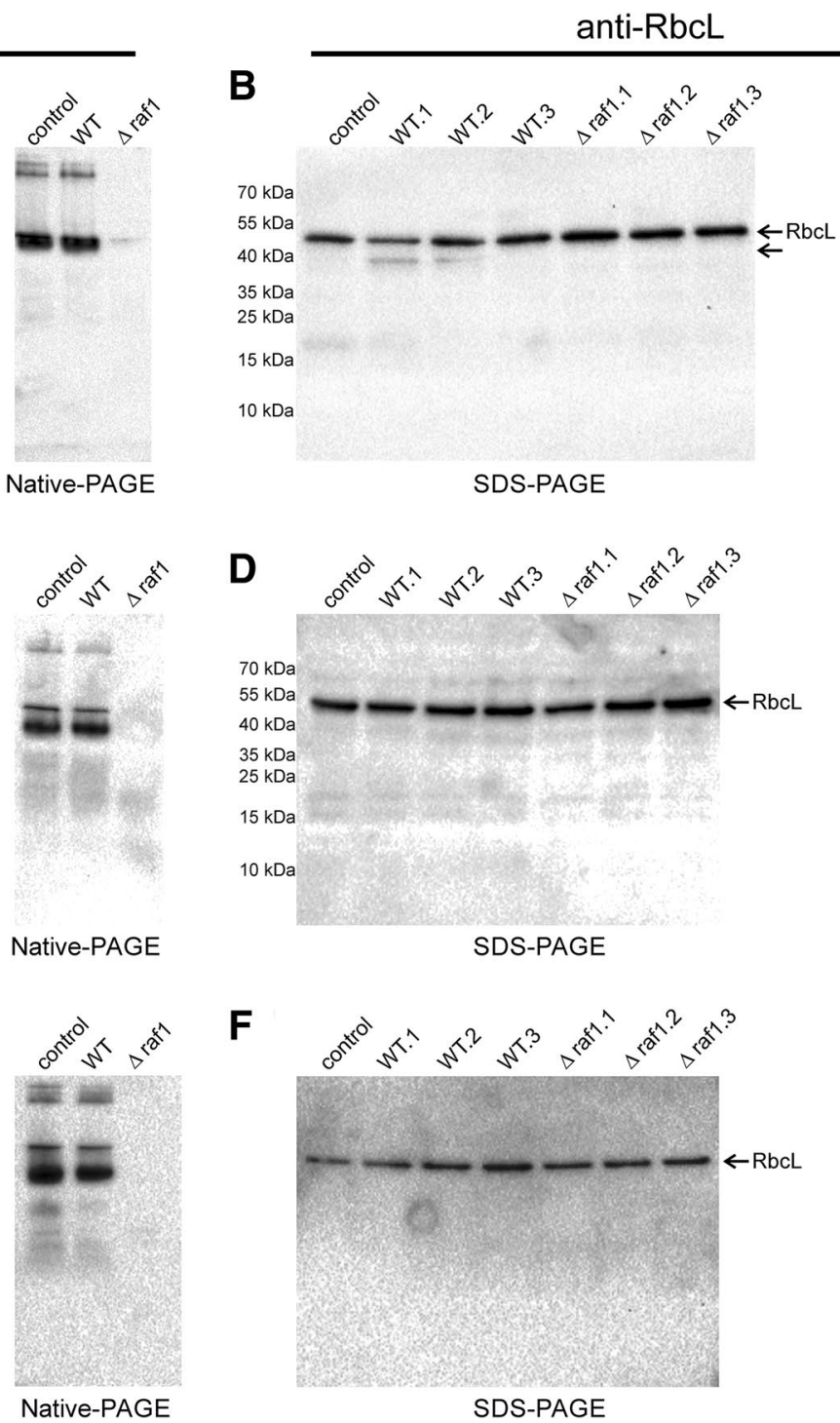

Native-PAGE

Fig. 3 Comparison of RbcL and RAF1 amounts and composition of RbcL- and RAF1-containing complexes in wild-type and $\Delta$ rafl Synechocystis cells subjected to sulfur starvation as well as oxidative and salt stress. A total of $20 \mu \mathrm{g}$ of protein extracts from wild-type and mutant cells were loaded per lane, separated under denaturing (SDSPAGE; extracts from three independent cultures were used) or non-

Synechocystis; therefore, we decided to use this to verify whether there is a probability of the subsequent action of $\mathrm{RAF} 1$ and $\mathrm{RbcX}$. The purified $\mathrm{RbcL}_{\mathrm{Te}}-\mathrm{RAF}_{6803}$ complex was mixed with $\mathrm{RbcX}_{6803}$ and $\mathrm{RbcL}_{\mathrm{Te}}-\mathrm{RbcX}_{6803}$ complex with $\mathrm{RAF} 1_{6803}$, incubated for $10 \mathrm{~min}$ at room temperature and subjected to native-PAGE. $\mathrm{RAF}_{6803}$ and $\mathrm{RbcX}_{6803}$ were also mixed in the same manner to verify occurrence of their putative interaction. While RAF1 readily bound to RbcL-RbcX complex, RbcX was not able to replace RAF1 from $\mathrm{RbcL}_{\mathrm{Te}}-\mathrm{RAF1}_{6803}$, even in a two-fold mass excess. No direct interaction between RAF1 and RbcX was observed using the described approach (Fig. 6c).
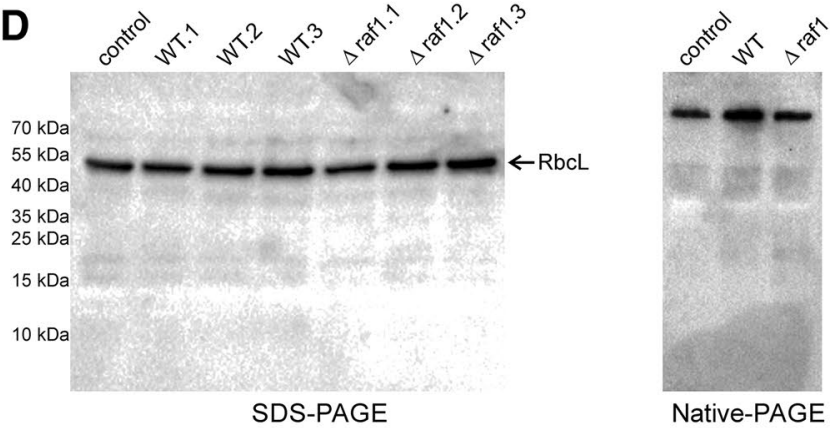

$\mathbf{F}$
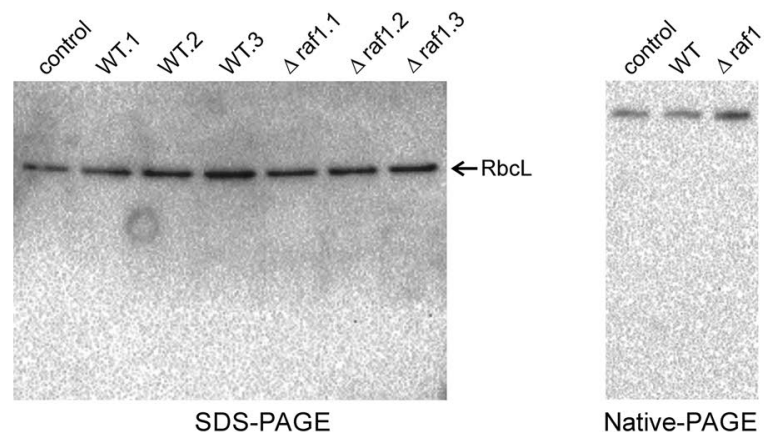

Native-PAGE

denaturing conditions (Native-PAGE) and subjected to immunodetection using anti-RAF1 (left panel $\mathbf{a}$ sulfur starvation, $\mathbf{c}$ oxidative stress, e salt stress) or anti-RbcL (right panel $\mathbf{b}$ sulfur starvation, $\mathbf{d}$ oxidative stress, $\mathbf{f}$ salt stress) antibodies. As a control, protein extract from untreated wild-type cells was used

\section{Discussion}

Since plants as well as many cyanobacteria contain both $\mathrm{RbcX}$ - and RAF1-encoding genes, it is unclear whether the two proteins participate during the same Rubisco assembly cycle or whether they mainly rely on one of these factors, whereas the function of the second is evolutionary obstructed. Such a hypothesis has mainly been directed toward plant Rubisco chaperones. There is unequivocal evidence for the requirement of RAF1 participation in plant holoenzyme biosynthesis (Feiz et al. 2012; Whitney et al. 2015), which is also supported by the confirmed presence 
Fig. 4 Effect of prolonged exposure to sulfur deprivation and subsequent sulfate repletion for wild-type and $\Delta$ rafl Synechocystis cells. Independent cyanobacterial cultures were transferred to sulfur-depleted BG-11 medium and grown subsequently for an additional 3 , 5 , or 7 days. a A total of $20 \mu \mathrm{g}$ of crude protein extracts from cells collected after treatment were loaded per lane, separated under denaturing conditions, and probed with anti-RbcL antibodies (b). The ability of both strains to recover after sulfur depletion was tested by direct supplementation of starved cultures with $\mathrm{MgSO}_{4}$ after 3, 5, or 7 days of treatment. $\mathbf{c}$ A total of $20 \mu \mathrm{g}$ of crude protein extracts from cells collected after 2-day sulfate re-supplementation were loaded per lane, separated under denaturing conditions, and probed with anti-RbcL antibodies (d). Positions of proteins with altered amounts specific for "mild starvation phenotype" of mutant cells are indicated with arrows. e Absorbance spectra of wild-type and mutant cells were measured after 7 days of sulfur starvation and following $48 \mathrm{~h}$ of sulfate re-supplementation (f; control-untreated wild-type cells)

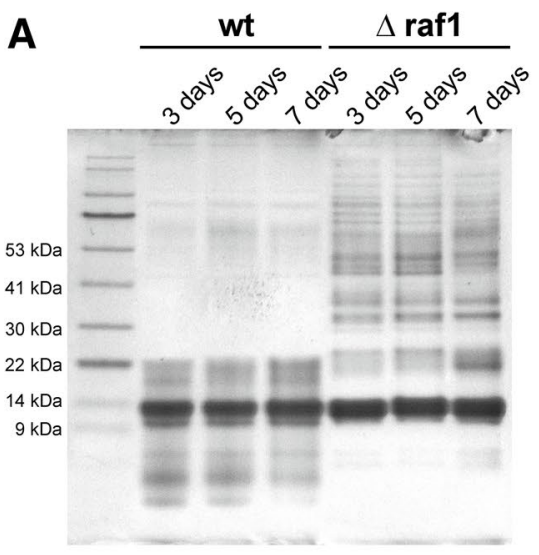

B

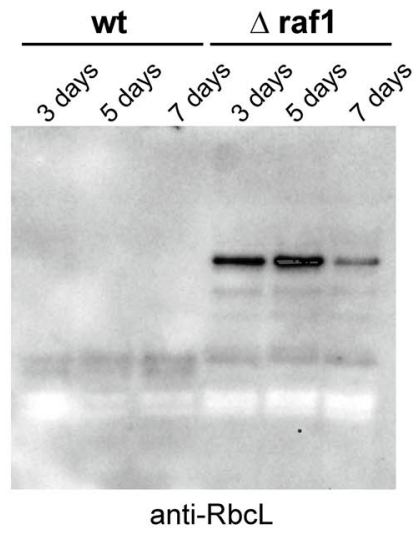

C

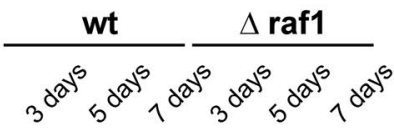

D

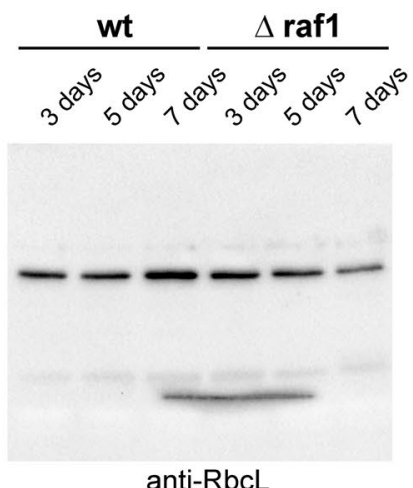

anti-RbcL
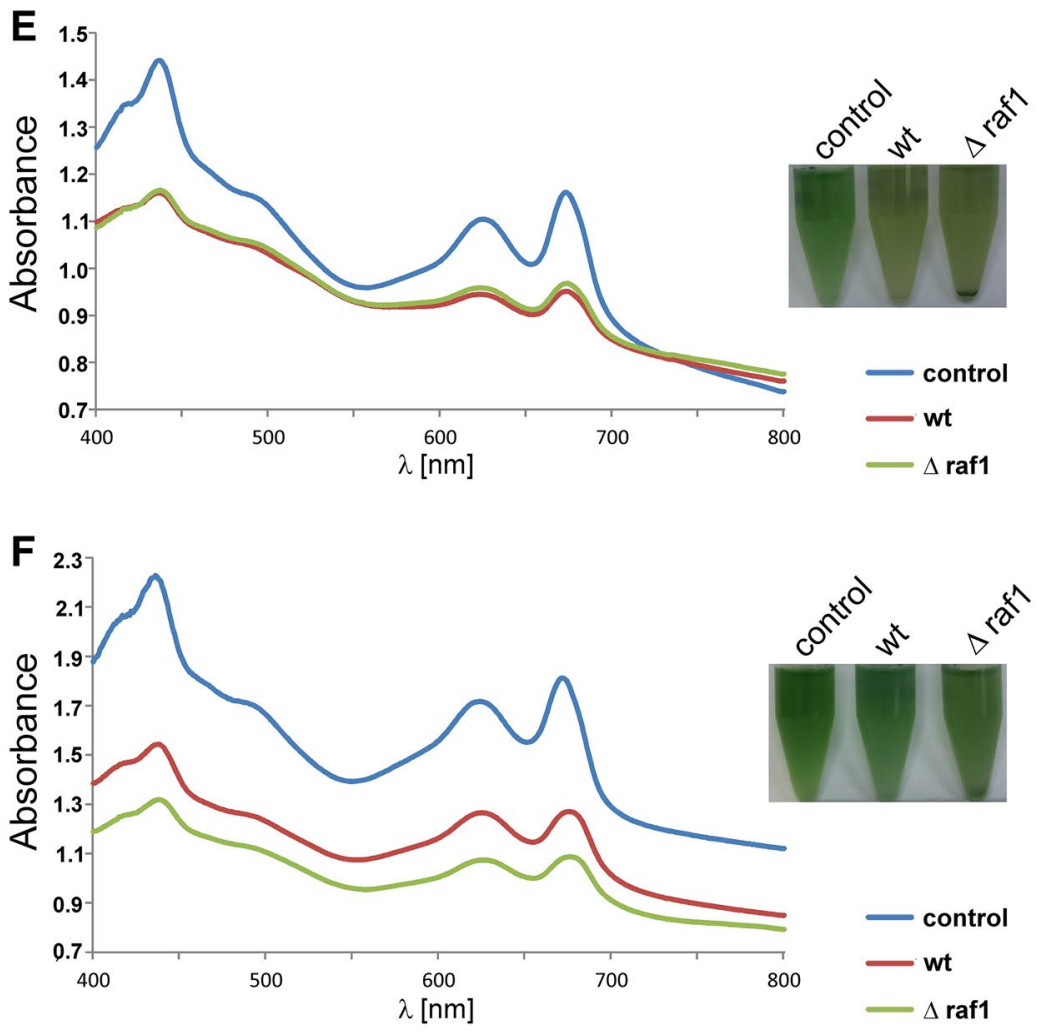


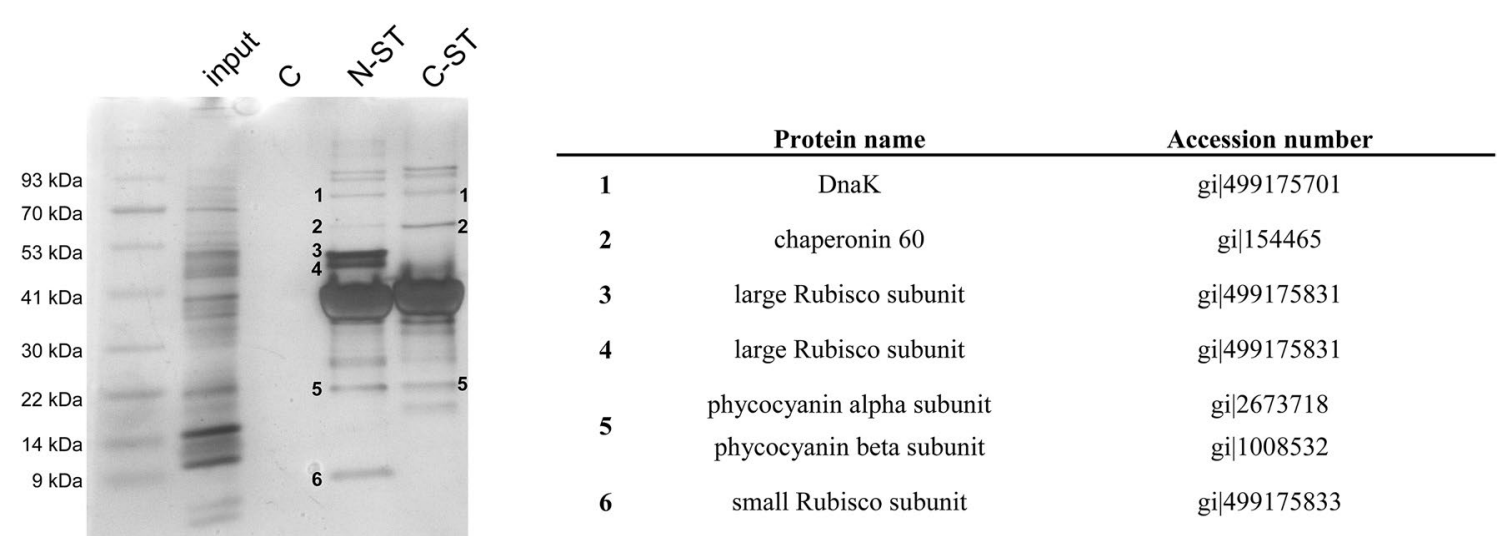

Fig. 5 Identification of putative RAF1-interacting proteins in cyanobacterial cells. Crude protein extracts from Synechocystis sp. PCC 6803 were incubated with $\mathrm{N}$ - (N-ST) or C-terminally (C-ST) labeled RAF1 and subjected to a pull-down experiment using Strep-Tactin Superflow Plus resin. As a control, cell extracts without the addition of labeled RAF1 were used (C). Eluted proteins were separated under

of this polypeptide in the chloroplast proteome (Friso et al. 2010). In contrast, RbcX on a protein level has never been directly identified in plant extracts, although $r b c X$ genes are transcribed in eukaryotic cells (Kolesinski et al. 2011; Ramegowda et al. 2014). On the other hand, RbcX was, for a long time, the only known prokaryotic Rubisco assembly chaperone and no performed cyanobacterial holoenzyme assembly assays have ever indicated the need for additional specialized factors (Liu et al. 2010; Mueller-Cajar and Whitney 2008; Larimer and Soper 1993).

Our results suggest that RAF1 from Synechocystis sp. PCC 6803 is not required for Rubisco assembly from this organism. Disruption of the rafl gene does not seem to affect cell viability, growth, or either the amount or the formation of Rubisco. However, in contrast to plant RbcX, this particular polypeptide is detectable by western blot in cyanobacterial extracts. Moreover, similar to maize cells (Feiz et al. 2012) or in vitro assays (Kolesinski et al. 2014; Hauser et al. 2015), its various oligomeric states have been observed. On the other hand, there are published examples of situations where deletion of particular chaperone did not result in obvious phenotypes in cases of the existence of additional factors with overlapping specificity. For example, disruption of the DnaK- or trigger factor-encoding gene alone in $E$. coli cells does not have any observable effect in terms of cell growth or protein folding (Deuerling et al. 1999). However, combined $\Delta d n a K / \Delta t i g$ mutation causes cell lethality. To fully understand the function and, if it exists, reciprocal dependence of RbcX and RAF1 in Rubisco biosynthesis, it would be necessary to generate a double $\Delta r b c X / \Delta r a f 1$ mutant of cyanobacterial cells. Since direct $r b c X$ insertion, such as that described by denaturing conditions and silver-stained. Separate protein bands were excised from gel and their polypeptide composition was identified by mass spectrometry. Polypeptides which are not RAF1 proteolysis or aggregation products are indicated with subsequent numbers and specified in the table

Onizuka et al. (2004) for Synechococcus sp. PCC 7002, or its replacement by antibiotic resistance cassette may have a downstream effect on $r b c S$ expression, it could be necessary to introduce clean and stable $r b c L-r b c S$ in place of an existing Rubisco operon.

As RAF1 obviously was unnecessary for cell viability under standard conditions, there is a possibility that its demand could be triggered by certain external stimuli. Among the tested stress conditions, the only differences between wild-type and mutant cells were observed during sulfur starvation, whereas prolonged oxidative stress exposition caused massive protein degradation in both types of cells (results not shown). However, sulfur depletioninduced phenotypes of wild-type and $\Delta$ rafl cells seem to be peculiar, given the fact that RAF1 was expected to be a Rubisco assembly chaperone and/or fulfill a Rubiscoprotective function. On the other hand, cyanobacterial RAF1 as a Rubisco-binding protein could participate in the holoenzyme degradation pathway. Plant Rubisco has been reported to be proteolyzed in the face of demand for amino acids during leaf senescence or nitrogen starvation periods (Feller et al. 2008). Ribulose-1,5-bisphosphate carboxylase/oxygenase degradation has also been observed during sulfur starvation for common duckweed (Lemna minor), without causing the death of this organism (Ferreira and Teixeira 1992). Since the cyanobacterial enzyme contributes to only about a few percent of total cellular protein mass due to the existence of a carbon concentrating mechanism (Raven 2013), it is unlikely that it can be used as a primary amino acid source, in contrast to its plant counterpart. However, sulfur requirement- and/or senescence-activated Rubisco proteolysis could be a signal for degradation 

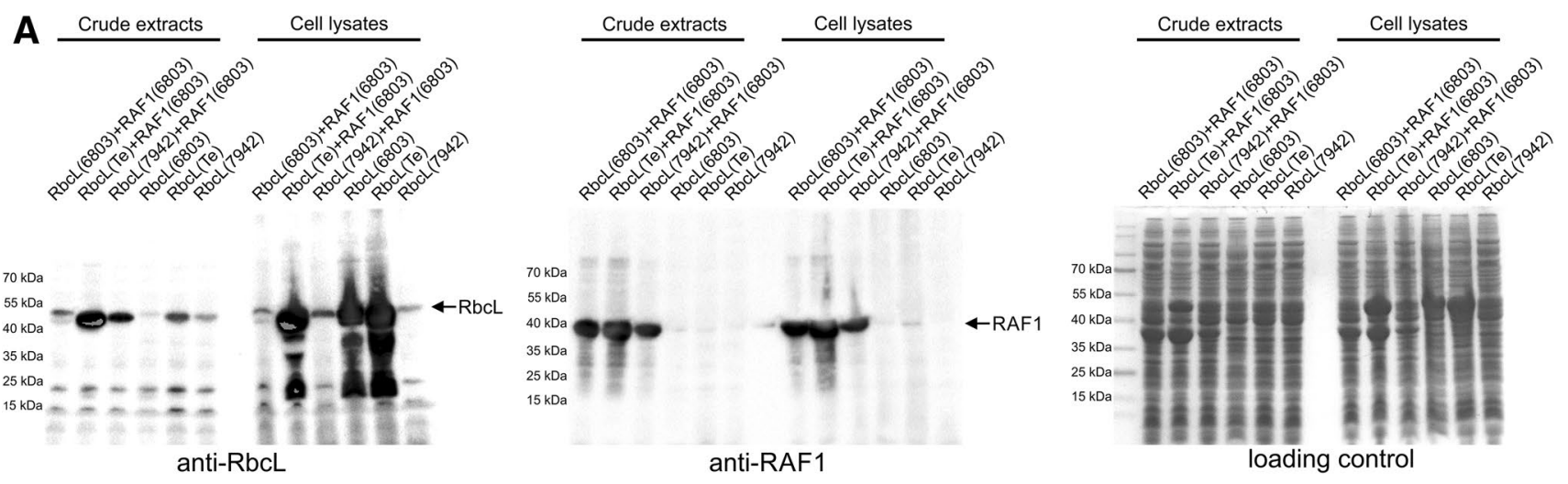

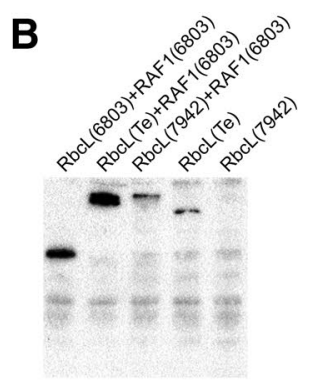

anti-RbcL

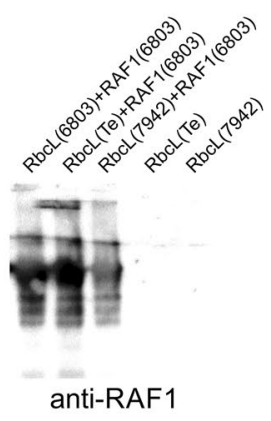

anti-RAF1
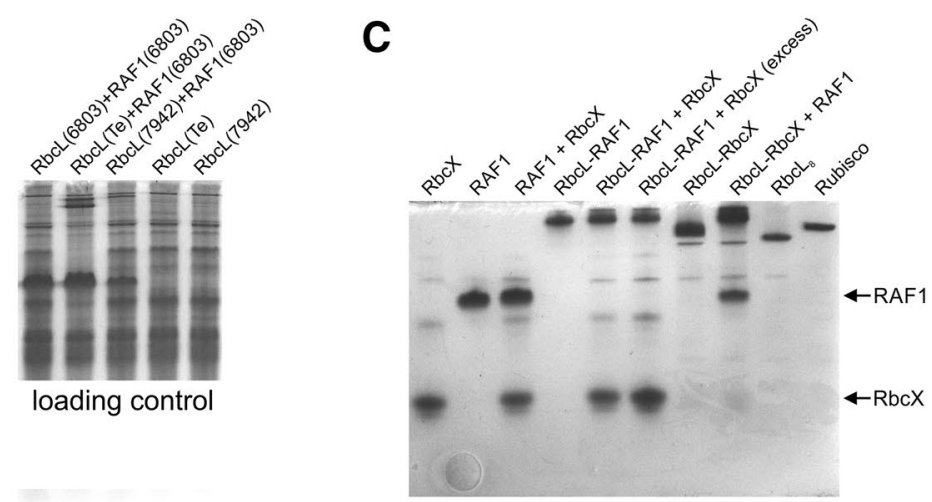

Fig. 6 Determination of RAF1 chaperone activity toward cyanobacterial RbcL. a Co-expression of rafl gene from Synechocystis sp. PCC 6803 with rbcL from Synechocystis sp. PCC 6803 (6803), Thermosynechococcus elongatus (Te) or Synechococcus elongatus PCC 7942 (7942) in E. coli cells. As a control, cells expressing $r b c L$ genes alone were used. $20 \mu \mathrm{g}$ of crude extracts as well as cell lysates from $E$. coli cells were separated under denaturing conditions (SDS-PAGE) and subjected to immunodetection using anti-RbcL or anti-RAF1 antibodies (a). Extracts with confirmed soluble RbcL presence were additionally separated under non-denaturing conditions (Native-PAGE) and probed with anti-RbcL or anti-RAF1 anti-

of high-molecular weight polypeptides. Whether RAF1 actively participates in such a process remains unclear, since pull-down experiments do not identify as RAF1 interactors any expected proteolytic enzymes, such as Clp (Olinares et al. 2011) or HtrA/Deg (Cheregi et al. 2016) proteases, but rather chaperones-DnaK2 or Cpn60. On the other hand, RAF1 seems to interact with both fulllength and slightly truncated RbcL forms, as judged by silver staining and mass spectrometry analysis. The latter has previously been reported to be incorporated into the plant holoenzyme during simultaneous action of putative cysteine endopeptidase (Thoenen et al. 2007). In theory, cyanobacterial RAF1 could be involved in a similar process by incorporation of non-functional subunits into the holoenzyme, "labeling" such structures for degradation.

Another explanation for observed sulfur depletion phenotypes may be RAF1 involvement in control machinery bodies (b). c Identification of mutual RAF1-RbcL-RbcX interactions. A total of $2.5 \mu \mathrm{g}$ (or $5 \mu \mathrm{g}$ in lanes where "excess" is indicated) of $\mathrm{RAF1}_{6803}, \mathrm{RbcX}_{6803}$ proteins as well as $\mathrm{RbcL}_{\mathrm{Te}}-\mathrm{RAF}_{6803}$ or $\mathrm{RbcL}_{\mathrm{Te}}{ }^{-}$ $\mathrm{RbcX}_{6803}$ complex were loaded either directly or after pre-incubation with its putative interactor on non-denaturing gel and separated. As a control for complex migration, $\mathrm{RbcL}_{8}$ and Rubisco $\left(\mathrm{RbcL}_{8} \mathrm{RbcS}_{8}\right)$ from T. elongatus were used. Positions of unbound RbcX and RAF1 are indicated with arrows. Addition of RAF1 resulted in an upshift of the $\mathrm{RbcL}_{\mathrm{Te}}-\mathrm{RbcX}_{6803}$ complex, whereas no substitution of RAF1 in $\mathrm{RbcL}_{\mathrm{Te}}-\mathrm{RAF}_{6803}$ by $\mathrm{RbcX}$ or direct interaction between RAF1 and $\mathrm{RbcX}$ was observed

related to the Rubisco biosynthesis process. Recently, Klotz et al. (2016) described a highly orchestrated program accompanying long-term nitrogen starvation-induced chlorosis of Synechocystis cells and resuscitation from this state caused by nitrogen source addition. In face of nutrient absence, cyanobacteria switch their metabolism from photosynthesis to glycogen storage, which is accompanied by photosynthetic enzyme degradation. Upon nitrate re-supplementation, cells suppress residual photosynthetic activity, and activate glycogen degradation mechanisms to re-switch to photosynthesis and vegetative growth after $48 \mathrm{~h}$. This sophisticated mechanism is employed to face long-term starvation periods as well as a colonization of new environments. In the absence of macro- or micronutrients, cells have to perform some sort of resource allocation, manifesting in degradation of selected polypeptides and/or photosynthetic pigments, to adapt to new conditions or to 
survive unfavorable periods (Fraser et al. 2013; Kiyota et al. 2014). Therefore, the lack of severe polypeptide fragmentation observed in $\Delta$ rafl cells could result from dysfunction of mechanisms switching cell metabolism to alternate paths of nutrient acquisition. A similar, although manifesting mainly in perturbed pigment degradation, effect has previously been observed for non-bleaching $\triangle$ nblA cyanobacterial mutants under nitrogen (Kiyota et al. 2014) or sulfur depletion (Yu et al. 2015). Although the $\Delta$ rafl strain could maintain its standard proteome for a longer period under sulfur starvation, prolonged exposure to stress stimuli could eventually lead to cell death due to its decreased adaptive abilities as observed for sulfate-repletion experiments.

Co-expression of Synechocystis rafl with an $r b c L$ gene from the same organism resulted in formation of a complex with a migration pattern resembling that of $\mathrm{RbcL}_{2}-\mathrm{RAF}_{2}$ in opposition to higher molecular weight mixed complexes (RAF1 from Synechocystis with RbcL from either $T$. elongatus or $S$. elongatus). No presence of $\mathrm{RbcL}$ in such $\left(\mathrm{RbcL}_{2}-\mathrm{RAF}_{2}\right)$ structures was confirmed for cyanobacterial extracts, probably due to their low amount-below the level of detection of anti-RbcL antibodies, although the position of some RAF1-containing complexes during native-PAGE separation might indicate their presence. $\mathrm{RbcL}_{2}-\mathrm{RAF}_{2}$, if it is not an artifact observable only in vitro and in E. coli cells, might be an important control point rather than a Rubisco assembly intermediate. Our previous report indicated that disassembly of an $\mathrm{RbcL}$ octamer by RAF1 is preferred over $\mathrm{RbcS}$ addition to $\mathrm{RbcL}_{2}-\mathrm{RAF}_{2}$ (Kolesinski et al. 2014). Therefore, faced with RbcS absence resulting from its proteolytic degradation or translational arrest, RbcL octamers could be dissociated by RAF1. Whether $\mathrm{RbcL}_{2}-\mathrm{RAF} 1_{2}$ could actively trigger transcriptional activation of various proteases or subsequent proteolytic events are the result of a cascade initiated by, e.g., a decline of Calvin-Benson-Bassham cycle metabolites remains unknown. The existence of such regulatory mechanisms, even if not involving RAF1, may be indicated by the presence of RbcS- (but not RbcL) specific protease HhoA in Synechocystis cells (Tam et al. 2015). To identify additional RAF1-interactors that could be involved in such putative control machinery, it would be necessary to obtain the Synechocystis mutant expressing the tagged variant of RAF1. When an exogenous protein is added to the cell extracts, a non-physiological interaction may be observed. In addition, some weak interaction might be overlooked due to the high level of peptides resulting from RAF1 fragmentation or simply because of the absence of some interactors which are only expressed under certain environmental conditions.

Surprisingly, in contrast to our previously reported results (i.e., Kolesinski et al. 2014), we were able to observe spontaneous formation of an T. elongatus $\mathrm{RbcL}$ octamer in the absence of any assembly chaperones in $E$. coli cells. This particular effect might result from the quality of water used for LB medium preparation (MiliQ vs. previously used distilled water), since when our standard approach was employed, Rubisco from Synechocystis sp. PCC 6803 was also not foldable in $E$. coli cells, when expressed with either RbcX- or RAF1-encoding genes. Although RAF1 promotes or significantly improves cyanobacterial RbcL folding, an experimental approach employing easily foldable Rubisco from T. elongatus (Kolesinski et al. 2014) or S. elongatus PCC 7942 (Hauser et al. 2015) for assembly chaperone analysis may falsify the true physiological function of the latter, despite its feasibility in the study of the mechanisms of action of these proteins. Therefore, RAF1 can act as a Rubisco assembly chaperone in E. coli because of its RbcL-stabilizing properties, although this may not necessarily be its proper purpose in cyanobacterial cells. Moreover, its obligatory chaperone function might be acquired during evolution and be revealed only in the plant cell. Various functions fulfilled by protein orthologs from different photosynthetic organisms are not uncommon and their examples have already been described in the literature (Belcher et al. 2015). Escherichia coli DnaK/DnaJ or GroEL/GroES systems may additionally mimic specialized cyanobacterial (but not eukaryotic) Rubisco-interacting proteins at pre-assembly Rubisco biogenesis stages. The existence of such particular factors as interacting with RbcL nascent chain Bsd2 (Doron et al. 2014) or specialized Cpn60 subunits required for rice RbcL folding (Kim et al. 2013) has been confirmed for eukaryotic cells.

Acknowledgements This study was supported by grant 2013/09/D/ NZ1/00185 from the National Science Center (NCN), Poland. The equipment used for MS protein identification was sponsored in part by the Center for Preclinical Research and Technology (CePT), a project co-sponsored by the European Regional Development Fund and Innovative Economy, The National Cohesion Strategy of Poland.

Open Access This article is distributed under the terms of the Creative Commons Attribution 4.0 International License (http:// creativecommons.org/licenses/by/4.0/), which permits unrestricted use, distribution, and reproduction in any medium, provided you give appropriate credit to the original author(s) and the source, provide a link to the Creative Commons license, and indicate if changes were made.

\section{References}

Barraclough R, Ellis RJ (1980) Protein synthesis in chloroplasts. IX. Assembly of newly-synthesized large subunits into ribulose bisphosphate carboxylase in isolated intact pea chloroplasts. Biochim Biophys Acta 608:18-31

Belcher S, Williams-Carrier R, Stiffler N, Barkan A (2015) Largescale genetic analysis of chloroplast biogenesis in maize. Biochim Biophys Acta 1847(9):1004-1016 
Bracher A, Starling-Windhof A, Hartl FU, Hayer-Hartl M (2011) Crystal structure of a chaperone-bound assembly intermediate of form I Rubisco. Nat Struct Mol Biol 18(8):875-880

Brutnell TP, Sawers RJ, Mant A, Langdale JA (1999) BUNDLE SHEATH DEFECTIVE2, a novel protein required for posttranslational regulation of the $\mathrm{rbcL}$ gene of maize. Plant Cell 11(5):849-864

Deuerling E, Schulze-Specking A, Tomoyasu T, Mogk A, Bukau B (1999) Trigger factor and DnaK cooperate in folding of newly synthesized proteins. Nature 400(6745):693-696

Doron L, Segal N, Gibori H, Shapira M (2014) The BSD2 ortholog in Chlamydomonas reinhardtii is a polysome-associated chaperone that co-migrates on sucrose gradients with the rbcL transcript encoding the Rubisco large subunit. Plant J 80(2):345-355

Emlyn-Jones D, Woodger FJ, Price GD, Whitney SM (2006) RbcX can function as a rubisco chaperonin, but is non-essential in Synechococcus PCC7942. Plant Cell Physiol 47(12):1630-1640

Feiz L, Williams-Carrier R, Wostrikoff K, Belcher S, Barkan A, Stern DB (2012) Ribulose-1,5-bis-phosphate carboxylase/oxygenase accumulation factor 1 is required for holoenzyme assembly in maize. Plant Cell 24(8):3435-3446

Feiz L, Williams-Carrier R, Belcher S, Montano M, Barkan A, Stern DB (2014) A protein with an inactive pterin-4a-carbinolamine dehydratase domain is required for Rubisco biogenesis in plants. Plant J 80(5):862-869

Feller U, Anders I, Mae T (2008) Rubiscolytics: fate of Rubisco after its enzymatic function in a cell is terminated. J Exp Bot 59(7):1615-1624

Ferreira RM, Teixeira AR (1992) Sulfur starvation in Lemna leads to degradation of ribulose-bisphosphate carboxylase without plant death. J Biol Chem 267(11):7253-7257

Fraser JM, Tulk SE, Jeans JA, Campbell DA, Bibby TS, Cockshutt AM (2013) Photophysiological and photosynthetic complex changes during iron starvation in Synechocystis sp. PCC 6803 and Synechococcus elongatus PCC 7942. PLoS One 8(3):e59861

Friso G, Majeran W, Huang M, Sun Q, van Wijk KJ (2010) Reconstruction of metabolic pathways, protein expression, and homeostasis machineries across maize bundle sheath and mesophyll chloroplasts: Large-scale quantitative proteomics using the first maize genome assembly. Plant Physiol 152:1219-1250

Goloubinoff P, Gatenby AA, Lorimer GH (1989) GroE heatshock proteins promote assembly of foreign prokaryotic ribulose bisphosphate carboxylase oligomers in Escherichia coli. Nature 337:44-47

Grigorieva G, Shestakov S (1982) Transformation in the cyanobacterium Synechocystis sp. PCC 6803. FEMS Microbiol Lett 13:367-370

Gubernator B, Bartoszewski R, Kroliczewski J, Wildner G, Szczepaniak A (2008) Ribulose-1,5-bisphosphate carboxylase/oxygenase from thermophilic cyanobacterium Thermosynechococcus elongatus. Photosynth Res 95(1):101-109

Hauser T, Bhat JY, Miličić G, Wendler P, Hartl FU, Bracher A, Hayer-Hartl M (2015) Structure and mechanism of the Rubiscoassembly chaperone Raf1. Nat Struct Mol Biol 22(9):720-728

He Y, Yu C, Zhou L, Chen Y, Liu A, Jin J, Hong J, Qi Y, Jiang D (2014) Rubisco decrease is involved in chloroplast protrusion and Rubisco-containing body formation in soybean (Glycine max.) under salt stress. Plant Physiol Biochem 74:118-124

Hernandez-Prieto M, Futschik ME (2012) CyanoEXpress: a web database for interactive exploration and visualisation of the integrated transcriptome of cyanobacterium Synechocystis sp. PCC6803. Bioinformation 8(13):634-638

Kanesaki Y, Suzuki I, Allakhverdiev SI, Mikami K, Murata N (2002) Salt stress and hyperosmotic stress regulate the expression of different sets of genes in Synechocystis sp. PCC 6803. Biochem Biophys Res Commun 290(1):339-348
Kim SR, Yang JI, An G (2013) OsCpn60 1 1, encoding the plastid chaperonin $60 \alpha$ subunit, is essential for folding of RbcL. Mol Cells 35(5):402-409

Kiyota H, Hirai MY, Ikeuchi M (2014) NblA1/A2-dependent homeostasis of amino acid pools during nitrogen starvation in Synechocystis sp. PCC 6803. Metabolites 4(3):517-531

Kolesinski P, Piechota J, Szczepaniak A (2011) Initial characteristics of RbcX proteins from Arabidopsis thaliana. Plant Mol Biol 77(4-5):447-459

Kolesinski P, Belusiak I, Czarnocki-Cieciura M, Szczepaniak A (2014) Rubisco Accumulation Factor 1 from Thermosynechococcus elongatus participates in the final stages of ribulose-1,5-bisphosphate carboxylase/oxygenase assembly in Escherichia coli cells and in vitro. FEBS J 281(17):3920-3932

Larimer FW, Soper TS (1993) Overproduction of Anabaena 7120 ribulose-bisphosphate carboxylase/oxygenase in Escherichia coli. Gene 126(1):85-92

Li LA, Tabita FR (1997) Maximum activity of recombinant ribulose 1,5-bisphosphate carboxylase/oxygenase of Anabaena sp. strain CA requires the product of the $r b c X$ gene. J Bacteriol 179(11):3793-3796

Li H, Singh AK, McIntyre LM, Sherman LA (2004) Differential gene expression in response to hydrogen peroxide and the putative PerR regulon of Synechocystis sp. strain PCC 6803. J Bacteriol 186(11):3331-3345

Liu C, Young AL, Starling-Windhof A, Bracher A, Saschenbrecker $\mathrm{S}$, Rao BV, Rao KV, Berninghausen O, Mielke T, Hartl FU, Beckmann R, Hayer-Hartl M (2010) Coupled chaperone action in folding and assembly of hexadecameric Rubisco. Nature 463:197-202

Mortz E, Krogh TN, Vorum H, Görg A (2001) Improved silver staining protocols for high sensitivity protein identification using matrix-assisted laser desorption/ionization-time of flight analysis. Proteomics 1(11):1359-1363

Mueller-Cajar O, Whitney SM (2008) Evolving improved Synechococcus Rubisco functional expression in Escherichia coli. Biochem J 414(2):205-214

Olinares PD, Kim J, van Wijk KJ (2011) The Clp protease system; a central component of the chloroplast protease network. Biochim Biophys Acta 1807(8):999-1011

Onizuka T, Endo S, Akiyama H, Kanai S, Hirano M, Yokota A, Tanaka S, Miyasaka H (2004) The $r b c X$ gene product promotes the production and assembly of ribulose-1,5-bisphosphate carboxylase/oxygenase of Synechococcus sp. PCC7002 in Escherichia coli. Plant Cell Physiol 45(10):1390-1395

Ramegowda V, Basu S, Krishnan A, Pereira A (2014) Rice GROWTH UNDER DROUGHT KINASE is required for drought tolerance and grain yield under normal and drought stress conditions. Plant Physiol 166(3):1634-1645

Raven JA (2013) Rubisco: still the most abundant protein of Earth? New Phytol 198(1):1-3

Rippka R (1988) Isolation and purification of cyanobacteria. Methods Enzymol 167:3-27

Sage RF (2002) Variation in the kcat of Rubisco in C3 and C4 plants and some implications for photosynthetic performance at high and low temperature. J Exp Bot 53:609-620

Saschenbrecker S, Bracher A, Rao KV, Rao BV, Hartl FU, HayerHartl M (2007) Structure and function of RbcX, an assembly chaperone for hexadecameric Rubisco. Cell 129(6):1189-1200

Schagger H, von Jagow G (1987) Tricine-sodium dodecyl sulfatepolyacrylamide gel electrophoresis for the separation of proteins in the range from 1 to $100 \mathrm{kDa}$. Anal Biochem 166:368-379

Schneider CA, Rasband WS, Eliceiri KW (2012) NIH Image to ImageJ: 25 years of image analysis. Nat Methods 9:671-675

Tam LX, Aigner H, Timmerman E, Gevaert K, Funk C (2015) Proteomic approaches to identify substrates of the three Deg/HtrA 
proteases of the cyanobacterium Synechocystis sp. PCC 6803. Biochem J 468(3):373-384

Tarnawski M, Gubernator B, Kolesinski P, Szczepaniak A (2008) Heterologous expression and initial characterization of recombinant RbcX protein from Thermosynechococcus elongatus BP-1 and the role of RbcX in RuBisCO assembly. Acta Biochim Pol 55:777-785

Thoenen M, Herrmann B, Feller U (2007) Senescence in wheat leaves: is a cysteine endopeptidase involved in the degradation of the large subunit of Rubisco?. Acta Physiol Plant 29:339

Wheatley NM, Sundberg CD, Gidaniyan SD, Cascio D, Yeates TO (2014) Structure and identification of a pterin dehydrataselike protein as a ribulose-bisphosphate carboxylase/oxygenase
(RuBisCO) assembly factor in the $\alpha$-carboxysome. J Biol Chem 289(11):7973-7981

Whitney SM, Birch R, Kelso C, Beck JL, Kapralov MV (2015) Improving recombinant Rubisco biogenesis, plant photosynthesis and growth by coexpressing its ancillary RAF1 chaperone. Proc Natl Acad Sci U S A 112(11):3564-3569

Wu X, Zarka A, Boussiba S (2000) A simplified protocol for preparing DNA from filamentous cyanobacteria. Plant Mol Biol Rep 18:385-392

Yu J, Liberton M, Cliften PF, Head RD, Jacobs JM, Smith RD, Koppenaal DW, Brand JJ, Pakrasi HB (2015) Synechococcus elongatus UTEX 2973, a fast growing cyanobacterial chassis for biosynthesis using light and $\mathrm{CO}_{2}$. Sci Rep 30(5):8132 